\title{
The Development of S-Equol Diastereoisomer Specific ELISA
}

\author{
Takayuki Minekawa $^{1,2}$, Akira Kambegawa ${ }^{3}$, Kumiko Shindome ${ }^{1}$, Shizuka Takehara ${ }^{1}$, \\ Hidetoshi Arakawa ${ }^{2}$ \\ ${ }^{1}$ Biochemical Research Laboratory, Eiken Chemical Co., Ltd., Tochigi, Japan \\ ${ }^{2}$ School of Pharmaceutical Science, Showa University, Tokyo, Japan \\ ${ }^{3}$ Kambegawa Laboratory, Tokyo, Japan \\ Email: Takayuki_Minekawa@eiken.co.jp
}

Received April 9, 2012; revised May 2, 2012; accepted May 18, 2012

\begin{abstract}
Equol is a metabolite of soybean isoflavone, daidzein, and many health benefits are expected. Endogenous equol in urine is S-equol and mostly exists as glucuronate or sulfate conjugate. In this study we preliminary established the simple enzyme-linked immunosorbent assay (ELISA) without deconjugation, then developed the S-equol specific ELISA involves deconjugation showing high stereospecificity to S-equol without using stereospecific antibody. For the simple ELISA, we used a polyclonal antibody that targets the regions not influenced by inhibition by conjugation of glucuronate and sulfate and achieved the correlation coefficient; $r=0.975$, but the value was $30 \%$ lower than high performance liquid chromatography (HPLC). Developing upon this we invented the specific ELISA established from S-equol homogeneous combination for the standard and enzyme-labeled antigen to enhance stereospecificity. The correlation with HPLC was favorable: $r=0.986, \mathrm{y}=0.996 \mathrm{x}-6$. Compared to the previous method using $(\mathrm{R}, \mathrm{S})$-equol combination, cross-reactivity with R-equol was reduced from $65 \%$ to $13 \%$, and that with daidzein from $0.31 \%$ to $0.08 \%$, markedly increased in the specificity. This study is expected to be applied for both simple clinical researches, and stereospecific immunoassays in which specific antibody preparation is difficult.
\end{abstract}

Keywords: S-Equol; Diastereoisomer; Immunoassay; ELISA; Isoflavone; Deconjugation

\section{Introduction}

Studies on equol [7-hydroxy-3-(4'-hydroxyphenyl)-chromanol], a metabolite of soybean isoflavone, daidzein, have markedly advanced recently, and many health benefits such as preventive effects against lung cancer, prostate cancer, osteoporosis, and postmenopausal syndrome have been reported [1-7]. However, people who receive health benefits of equol are limited to equol producers possessing intestinal bacterial flora metabolizing daidzein to equol. The population of equol producers has been reported to be $30 \%-50 \%$ [8], and the rest, non-equol producers, do not receive the health benefits. Recently Uchiyama et al. isolated equol-producing bacteria and enabled direct ingestion of equol which raised a possibility that non-equol producers benefit similarly to equol producers $[9,10]$.

Equol producers have been identified by measuring urinary or serum equol. When researchers were searching for the health benefits of various isoflavones, equol was measured mainly employing instrumental analysis, such as high performance liquid chromatography (HPLC) and liquid chromatography-tandem mass spectrometry $(\mathrm{LC} /$ MS/MS) [11-13]. These methods are very useful to simul- taneously measure various soybean isoflavones, such as daidzein, genistein, and glystein. As the benefits of being an equol producer have been reported and direct equol ingestion by non-equol producers has become possible, however, the development of a simple and specific measurement method capable of processing a large number of samples from equol producers is awaited. To facilitate this, time-resolved fluoroimmunoassay (TR-FIA) $[14,15]$ and bioluminescent enzyme immunoassay (BLEIA) [16] employing the immunoassay principle have been reported. Because these methods require a time-resolution fluorescence detector and a special device to detect trace levels of emission, the use by general researchers is limited. Moreover, shortening of the measurement time has not been realized due to the time taken for a deconjugation treatment.

Because equol in blood and urine is mostly present in conjugate forms as in glucuronate and sulfate conjugates [17], equol has been measured using HPLC and LC/MS /MS, or special devices such as TR-FIA after deconjugation of the conjugates by enzymes like $\beta$-glucuronidase. It requires a time consuming process before a measurement. 
To administer equol to improve symptoms of postmenopausal syndrome, if an outpatient can be immediately identified as a non-equol producer, ingestion equol can be rapidly prescribed. In this study, firstly, we established a simple ELISA method without the deconjugation process to simply identify equol producers. Measurement without the deconjugation may lead to the development of other simpler methods such as immunochromatogaphy in the future.

Equol exists as diastereoisomers. Two forms, R- and $\mathrm{S}$-form, are mixed in many commercial synthetic equol reagents, whereas only S-form is produced by intestinal bacterial flora. Since the affinity for estrogen receptors is different between the S- and R-forms [18], it is necessary to specifically measure S-equol. But the major methods used today, HPLC, LC/MS/MS and TR-FIA, cannot stereospecifically measure S-equol. The measuring system we reported using BLEIA was able to, however it lacked commonality and easiness to be used among different research facilities. In this study we invented the S-equol specific ELISA using horse radish peroxidase (HRP) labeling that can be commonly used in addition to the Simple ELISA that does not require deconjugation process. Because pure S-equol is expensive, a problem arises with the use of large amount of S-equol for immunization. To resolve this we prepared antiserum with a low stereospecificity using inexpensive (R,S)-equol as an antigen, then used S-equol as the standard and the labeled antigen to establish a highly S-equol specific measurement system.

\section{Materials and Methods}

\subsection{Reagents}

$(\mathrm{R}, \mathrm{S})$-equol, daidzein, and genistein were purchased from LC Laboratories (Woburn, MA, USA). S-equol was purchased from Toronto Research Chemicals Inc. (Ontario, Canada). Daidzein, genistein, glycitein, estradiol, and formononetin were purchased from Sigma-Aldrich (St. Louis, MO, USA). Biochanin A was purchased from LKT Laboratories, Inc. (St. Paul, MN, USA). $\beta$-Glucuronidase Type II was purchased from Nippon Biotest Laboratories Inc. (Tokyo, Japan). Horse radish peroxidase (HRP) was purchased from TOYOBO Co., Ltd. (Osaka, Japan). N-hydroxysuccinimide (NHS) was purchased from Wako Pure Chemical Industries, Ltd. (Osaka, Japan). 1-Ethyl-3-(3-dimethylaminopropyl) carbodiimide, hydrochloride (EDC) was purchased from DOJINDO LABORATORIES (Kumamoto, Japan). Other reagents used were of analytical grade.

\subsection{Devices}

Microplate absorbance reader, MTP-450, CORONA ELECTRIC Co., Ltd. (Ibaraki, Japan) and Auto Mini Washer AMW-8, BIOTEC Co., Ltd. (Tokyo, Japan) were used.

\subsection{Goat Anti-Rabbit IgG-Coated Plate}

Coating solution $(10 \mu \mathrm{g} / \mathrm{ml}$ goat anti-rabbit $\mathrm{IgG}$ in $0.1 \mathrm{M}$ carbonate buffer, $\mathrm{pH}$ 10.0) was added to a 96-well microplate at $100 \mu \mathrm{l} /$ well, and the plate was incubated at $4^{\circ} \mathrm{C}$ for 2 nights. After coating, the wells were washed twice with washing/post-coating solution $(0.05 \mathrm{M}$ phosphate buffer, $\mathrm{pH} 7.3,3 \%$ sucrose, $0.05 \%$ BSA, bovine serum albumin), and $350 \mu \mathrm{l} /$ well of the same solution was added and incubated at $4^{\circ} \mathrm{C}$ overnight for post-coating. The post-coating solution was removed, and the plate was vacuum-dried to prepare a goat anti-rabbit IgGcoated plate.

\subsection{Antiserum}

For the immunogen, (R,S)-equol-carboxymethylether (CME)-BSA was synthesized employing the method reported by Minekawa et al. [16]. The synthesized immunogen was emulsified with Freund's adjuvant and subcutaneously injected into a rabbit 9 times at 3 weeks intervals, and antiserum was obtained following the standard method.

\subsection{HRP Conjugate: S-Equol-CPE-HRP and (R,S)-Equol-CPE-HRP}

S-equol-carboxypropylether (CPE) and (R,S)-equol-CPE was synthesized employing the method reported by Minekawa et al. [16] and $2.8 \mathrm{mg}$ of S-equol-CPE or (R,S)-equol-CPE was dissolved in $28 \mu \mathrm{l}$ of dimethyl sulfoxide (DMSO). It was followed by the addition of 2.1 $\mathrm{mg}$ of N-hydroxysuccinimide (NHS) and the same amount of 1-ethyl-3-(3-dimethylaminopropyl) carbodiimide hydrochloride (EDC), and mixing. The mixture was kept standing at $25^{\circ} \mathrm{C}$ for 60 minutes. After adding distilled water, Equol-CPE-NHS derivative was extracted with ethyl acetate. The organic phase was dehydrated with sodium sulfate and dried under a reduced pressure. The obtained derivative $0.96 \mathrm{mg}$ was dissolved together with $14.46 \mathrm{mg}$ of HRP in $50 \mathrm{mM}$ carbonate buffer, $\mathrm{pH} 9.6$ and reacted at room temperature for 30 minutes. The crude equol-CPE-HRP was separated from non-reacted equolCPE using PD-10 (GE Healthcare UK Ltd., Little Chalfont, UK). The HRP-containing fraction was collected and diluted with $100 \mathrm{mM}$ phosphate buffer, $\mathrm{pH} 7.5,150$ $\mathrm{mM}$ sodium chloride, $0.5 \%$ BSA, $0.01 \%$ Tween 20 , and $5.0 \mu \mathrm{g} / \mathrm{ml}$ lactoperoxidase. The prepared solutions were used as original S-equol-CPE-HRP and (R,S)-equolCPE-HRP solutions, respectively.

\subsection{HPLC}

Quantification employing HPLC was performed by SRL Inc. (Tokyo, Japan) using a partial modification of Franke's method [12]. 


\subsection{ELISA}

Twenty $\mu$ l of urine was combined with $200 \mu$ of sample dilution solution (100\% charcoal-treated human serum) and used as a diluted sample.

\subsubsection{Method 1: The Simple ELISA without Deconjugation Process}

To achieve reactivity without deconjugation process we used polyclonal antibody that targets the regions not influenced by inhibition by conjugation with glucuronate and sulfate.

To wells of the goat anti-rabbit IgG-coated plate, $20 \mu \mathrm{l}$ of a diluted sample or standard (R,S)-equol solution, 50 $\mu \mathrm{l}$ of assay buffer containing (R,S)-equol-CPE-HRP (150 $\mathrm{mM}$ sodium chloride, $0.5 \%$ BSA, $0.01 \%$ Tween 20,100 $\mathrm{mM}$ phosphate buffer, $\mathrm{pH} 7.5$ ), and $50 \mu \mathrm{l}$ of assay buffer containing rabbit anti-equol serum were added and mixed. The plate was incubated at $25^{\circ} \mathrm{C}$ for 1 hour. The reaction solution was removed, and the wells were washed 3 times with washing solution $(0.3 \mathrm{mM}$ phosphate buffer, $\mathrm{pH} 7.5$, containing $100 \mathrm{mM}$ sodium chloride and $0.025 \%$ Tween 20), followed by the addition of $100 \mu \mathrm{l}$ of substrate solution $(50 \mathrm{mM}$ citrate buffer, $\mathrm{pH} 5.5$, containing $0.05 \%$ aqueous hydrogen peroxide solution and $2.2 \mathrm{mg} / \mathrm{ml}$ OPD, o-phenylenediamine dihydrochloride), and the plate was incubated at $25^{\circ} \mathrm{C}$ for 30 minutes. After the reaction was stopped with the addition of $100 \mu \mathrm{l}$ of $1.5 \mathrm{M}$ sulfuric acid, the absorbance was measured at a 490-nm wavelength. The equol concentration in the diluted sample was determined based on the standard curve prepared from the serial standard dilution. The value from the curve was converted to the concentration in the original sample. When the concentration exceeded the measurement range, the sample was further diluted with the sample dilution solution and re-measured (Table 1).

\subsubsection{Methods 2-5: The S-Equol Specific ELISA}

To find a combination of standard and enzyme-labeled antigen, we tested four combinations of heterogenous and homogenous equol diastereoisomers.

To the goat anti-rabbit IgG-coated plate, $20 \mu \mathrm{l}$ of a diluted sample or standard equol solution and $50 \mu \mathrm{l}$ of equolCPE-HRP combined with enzyme solution $(0.1 \mathrm{M}$ acetate

Table 1. Combinations of equol diastereoisomers used in each method.

\begin{tabular}{cccccc}
\hline & & \multicolumn{4}{c}{ Equol diastereoisomer } \\
\cline { 3 - 6 } Method & Deconjugation & Standard & $\begin{array}{c}\text { Labeled } \\
\text { antigen }\end{array}$ & Antiserum & Sample \\
\cline { 3 - 6 } 1 & - & R,S & R,S & R,S & S \\
2 & + & R,S & R,S & R,S & S \\
3 & + & S & R,S & R,S & S \\
4 & + & R,S & S & R,S & S \\
5 & + & S & S & R,S & S \\
\hline
\end{tabular}

buffer, $\mathrm{pH} 5.5$, containing $6 \% \beta$-glucuronidase) were added and mixed. The plate was incubated at $25^{\circ} \mathrm{C}$ for $30 \mathrm{~min}-$ utes, followed by the addition of $50 \mu$ of assay buffer containing rabbit anti-equol antiserum and mixing. The plate was then incubated at $25^{\circ} \mathrm{C}$ for 1 hour and similarly processed as described above in Method 1. The combinations of the standard solution and equol-CPE-HRP were as follows. Method 2 used (R,S)-equol for both. Method 3 used S-equol and (R,S)-equol, respectively, Method 4 $(\mathrm{R}, \mathrm{S})$ and $\mathrm{S}$, and Method $5 \mathrm{~S}$ and $\mathrm{S}$ (Table 1).

\subsection{Time-Course Change in Urinary Equol Concentration}

The urinary equol concentration was measured before and after the ingestion of a soybean bar containing $19 \mathrm{mg}$ of isoflavone. Soybean food ingestion was limited to this soybean bar 12 hours prior to the ingestion until the completion of sample collection.

\section{Results and Discussion}

\subsection{The Simple ELISA}

The casual urine equol concentration was measured in 24 healthy Japanese employing the ELISA and HPLC methods, and the measured values were compared. The values measured employing ELISA with deconjugation process (Method 2) showed a favorable correlation $(r=$ $0.997, y=0.774 x+146)$. Those measured employing the simple ELISA without deconjugation (Method 1) were about 30\% lower than those measured by the HPLC method, but the correlation was favorable $(r=0.975, \mathrm{y}=$ $0.277 x+19)$ (Figure 1). The reduced values measured using the simple ELISA without deconjugation may have been due to the inhibition of reactions of polyclonal antibodies recognizing regions around the hydroxyl group of equol molecules because the hydroxyl group was conjugated with glucuronic and sulfuric acid in many urinary equol molecules. However, this measurement system can target regions not influenced by inhibition by conjugation because polyclonal antibodies are used, which may be applicable for quantitative measurement. Based on these findings, it is possible to measure urinary equol without deconjugation, the main obstacle to shortening the measurement time. Its application to simplify other methods such as immunochromatography is expected.

\subsection{The S-Equol Specific ELISA}

In the ELISA method (Method 2) established above, the values were $78 \%$ of those measured by the HPLC method, showing that the reduction of the measured values could not completely be resolved by deconjugation (Figure 1). The inhibition of the labeled $(\mathrm{R}, \mathrm{S})$-equol by urine sample containing only S-equol may have been less than the 


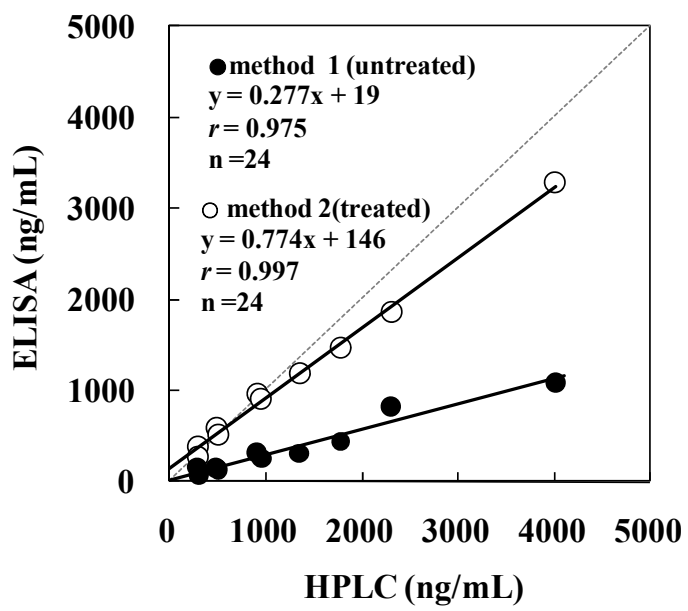

Figure 1. Correlation between the urinary equol concentrations measured employing the ELISA method and the HPLC method. Method 1 measured equol without deconjugation treatment. Method 2 measured after deconjugation by $\beta$-glucuronidase.

standard (R,S)-equol, resulting in a lower measured value. When a heterogeneous combination of S-form as the standard and (R,S)-form as the labeled antigen was employed (Method 3), the 50\% inhibitory concentration (IC50) on the standard curve was $723 \mathrm{ng} / \mathrm{ml}$, and that of another heterogeneous combination in Method 4 of $(\mathrm{R}, \mathrm{S})$ and $\mathrm{S}$, as the standard and the labeled antigen respectively, was $728 \mathrm{ng} / \mathrm{ml}$ showing lower inhibition rates than those in the homogenous combinations of Method 2 using (R,S), as the standard and the labeled antigen, showed $380 \mathrm{ng} / \mathrm{ml}$ and Method 5 using $\mathrm{S}$, as the standard and the labeled antigen, showed $444 \mathrm{ng} / \mathrm{ml}$. Accordingly, the measured values of the urine samples determined from these standard curves were higher than the values measured by HPLC by 1.5 times in Methods 3 and 1.4 times in Method 4 (Figure 2). Method 5 employing a homogenous combination, S-equol for both the standard and the enzyme-labeled antigen was the only method that its measured values were consistent with those by HPLC $(r=0.986, \mathrm{y}=0.996 \mathrm{x}-6, \mathrm{n}=15)$.

In addition, cross-reactivity with equol analogues was compared between Method 2 and Method 5, which employed homogenous combinations of $(\mathrm{R}, \mathrm{S})$, and $\mathrm{S}$, respectively. The cross-reactivity with R-equol was $65.73 \%$ in Method 2, and 13.24\% in Method 5. That with daidzein was $0.31 \%$ in Method 2, and $0.08 \%$ in Method 5, showing S-equol specificity markedly increased (Table 2). Based on these findings, Method 5 using S-equol for both the standard and the enzyme-labeled antigen was selected as the S-equol-specific measurement, and basic data were

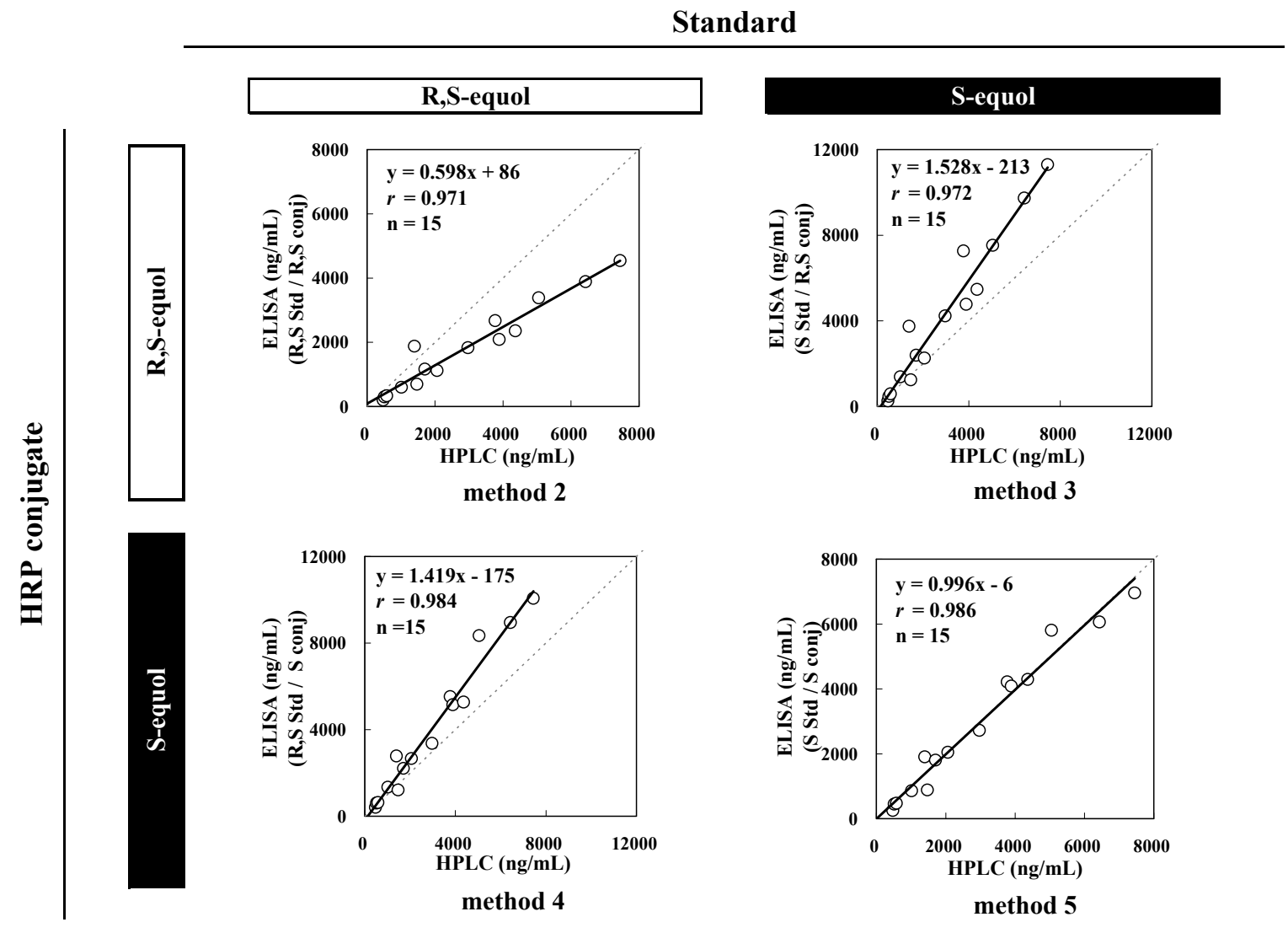

Figure 2. Correlation between the urinary equol concentrations measured employing the HPLC method and the ELISA method using different combinations of (R,S)-equol and S-equol for the standard and enzyme-labeled antigen. 
Table 2. Cross-reactivity of the equol ELISA compared between Methods 2 and 5 .

\begin{tabular}{ccc}
\hline \multirow{2}{*}{ Cross-reactivity with } & \multicolumn{2}{c}{ Cross-reactivity (\%) } \\
\cline { 2 - 3 } & method 2 & method 5 \\
\hline S-equol & 86.94 & 100.00 \\
R-equol & 65.73 & 13.24 \\
Daidzein & 0.31 & 0.08 \\
Genistein & 0.68 & 0.05 \\
Glycitein & 0.09 & 0.03 \\
Estradiol & 0.15 & 0.01 \\
Daidzin & 0.18 & 0.06 \\
Genistin & 0.36 & 0.06 \\
Biochanin A & 0.32 & 0.11 \\
Formononetin & 0.27 & 0.21 \\
\hline
\end{tabular}

collected. The standard curve showed a favorable line within a range of $36.3-8910 \mathrm{ng} / \mathrm{ml}$ (Figure 3). On precision profile analysis the concentration at which the coefficient of variation (CV) was lower than $10 \%$ was $330 \mathrm{ng} / \mathrm{ml}$ (data not shown), based on which the measurement range was set at $330-8910 \mathrm{ng} / \mathrm{ml}$. When 1 volume of equol at a known concentration was added to 9 volumes of urine, the recovery rate of equol was $71.1 \%$ $121.9 \%$ (Table 3). The CVs of the intra- and inter-assay reproducibility of human urinary equol (537 - 4008 $\mathrm{ng} / \mathrm{ml})$ measurement was $6.2 \%-8.1 \%(\mathrm{n}=8)$ and $3.5 \%$ $4.0 \%(n=12)$, respectively (Table 4).

The time-course change in urinary equol concentration after isoflavone ingestion was measured as a clinical application model (Figure 4). The urinary equol concentration reached its first peak of $790 \mathrm{ng} / \mathrm{ml}$ at 12.5 hours after isoflavone ingestion and then declined to below the detection limit at 14 hours. The concentration increased again, to $475 \mathrm{ng} / \mathrm{ml}$ at 16 hours, then reached its second peak of $729 \mathrm{ng} / \mathrm{ml}$ at 30.5 hours, and declined below the detection limit at 37 hours. The appearance of two peaks in the urinary equol level may have been due to enterohepatic circulation [19].

\section{Conclusions}

In this study we developed S-equol diastereomer specific ELISA (Method 5) by selecting S-equol for both the standard and the antigen labeled enzyme, which was improved from another novel invention of the simple ELISA (Method 1). Since the simple ELISA (Method 1) can measure equol without the deconjugation process, measuring equol in urine sample became more convenient, and its application for other methods such as immunochromatography is expected.

Since the specific ELISA (Method 5) not only shows a low cross reaction to R-equol and daidzein but also handles a large number of samples within a short period of time, the laboratory possessing only general equipments are able to carry out the studies on equol without special apparatus used for HPLC and LC/MS/MS. The utilizetion of this method in broad fields including epidemiological and biokinetic studies is expected.

We prepared antiserum with low stereospecificity, instead of S-equol-specific antibody by immunization with

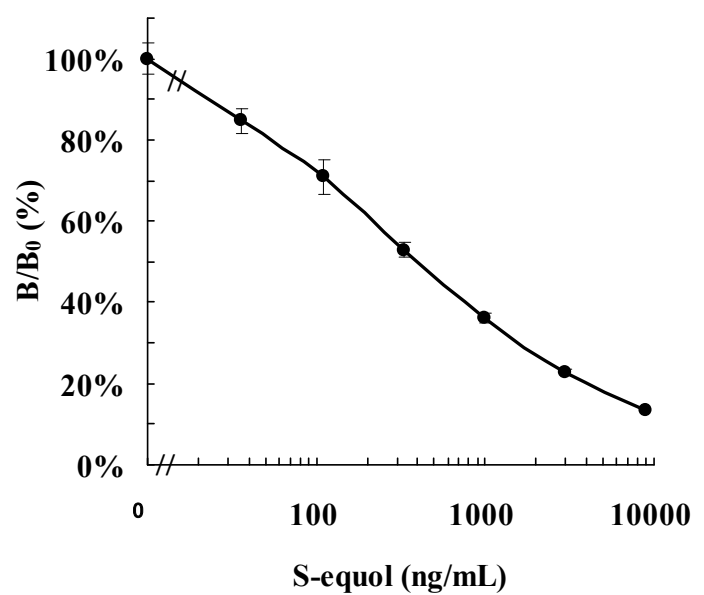

Figure 3. Standard curve of S-equol measured by the S-equol specific ELISA $(n=16$, mean $\pm 2.6 \mathrm{SD})$.

Table 3. Recovery test using urine samples in the S-equol specific ELISA.

\begin{tabular}{lcccc}
\hline Sample & Added & Observed & Recovered & Recovery \\
\hline & $(\mathrm{ng} / \mathrm{mL})$ & $(\mathrm{ng} / \mathrm{mL})$ & $(\mathrm{ng} / \mathrm{mL})$ & $(\%)$ \\
\hline Human & 300 & 472 & 0 & \\
Urine 1 & 900 & 1538 & 366 & 122 \\
& 2700 & 3326 & 1058 & 118 \\
& 0 & 1566 & 2854 & 106 \\
Human & 300 & 1869 & 303 & 101 \\
Urine 2 & 900 & 2506 & 940 & 104 \\
& 2700 & 4215 & 2648 & 98 \\
& 0 & 3322 & 0 & \\
Human & 300 & 3536 & 213 & 71 \\
Urine 3 & 900 & 4206 & 884 & 98 \\
& 2700 & 5995 & 2673 & 99 \\
\hline
\end{tabular}

Table 4. Reproducibility in the S-equol specific ELISA.

\begin{tabular}{cccc}
\hline Sample & $\begin{array}{c}\text { Concentration } \\
(\mathrm{ng} / \mathrm{mL})\end{array}$ & $\begin{array}{c}\text { Intra-assay } \\
\mathrm{CV}(\%)\end{array}$ & $\begin{array}{c}\text { Inter-assay } \\
\mathrm{CV}(\%)\end{array}$ \\
\hline Human Urine 4 & 537 & $8.1(\mathrm{n}=8)$ & $3.7(\mathrm{n}=12)$ \\
Human Urine 5 & 1775 & $6.2(\mathrm{n}=8)$ & $4.0(\mathrm{n}=12)$ \\
Human Urine 6 & 4008 & $7.1(\mathrm{n}=8)$ & $3.5(\mathrm{n}=12)$ \\
\hline
\end{tabular}




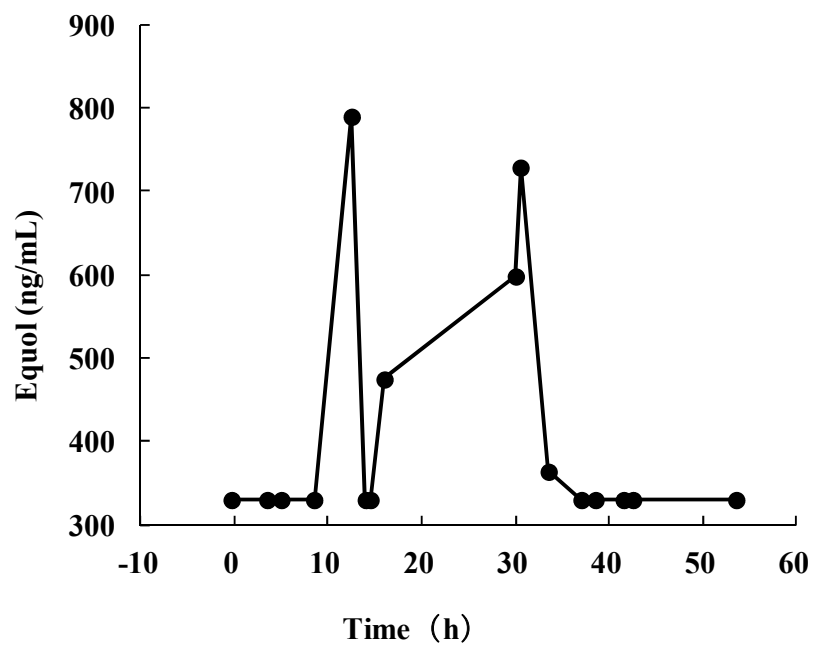

Figure 4. Time-course changes in the urinary equol concentration. The urinary equol concentration was measured before and after the ingestion intake of a soybean bar containing $19 \mathrm{mg}$ of isoflavone, regarding the time of ingestion as 0 hour.

$(\mathrm{R}, \mathrm{S})$-equol, and developed an S-equol-specific immunoassay system by a combination of S-equol HRP conjugate and this low stereospecific antiserum. This system is expected to be applied for a simple stereospecific immunoassay in which specific antibody preparation is difficult.

\section{REFERENCES}

[1] A. M. Duncan, B. E. Merz-Demlow, X. Xu, W. R. Phipps and M. S. Kurzer, "Premenopausal Equol Excretors Show Plasma Hormone Profiles Associated with Lowered Risk of Breast Cancer," Cancer Epidemiology, Biomarkers and Prevention, Vol. 9, No. 6, 2000, pp. 581-586.

[2] H. Akaza, N. Miyanaga, N. Takashima, S. Naito, Y. Hirao, T. Tsukamoto, T. Fujioka, M. Mori, W. J. Kim, J. M. Song and A. J. Pantuck, "Comparisons of Percent Equol Producers between Prostate Cancer Patients and Controls: Case-Controlled Studies of Isoflavones in Japanese, Korean and American Residents," Japanese Journal of Clinical Oncology, Vol. 34, No. 2, 2004, pp. 86-89. doi:10.1093/jjco/hyh015

[3] H. Akaza, N. Miyanaga, N. Takashima, S. Naito, Y. Hirao, T. Tsukamoto and M. Mori, "Is Daidzein NonMetabolizer a High Risk for Prostate Cancer? A CaseControlled Study of Serum Soybean Isoflavone Concentration," Japanese Journal of Clinical Oncology, Vol. 32, No. 8, 2002, pp. 296-300. doi:10.1093/jico/hyf064

[4] K. Ozasa, M. Nakao, Y. Watanabe, K. Hayashi, T. Miki, K. Mikami, M. Mori, F. Sakauchi, M. Washio, Y. Ito, K. Suzuki, K. Wakai, A. Tamakoshi and JACC Study Group, "Serum Phytoestrogens and Prostate Cancer Risk in a Nested Case-Control Study among Japanese Men," Cancer Science, Vol. 95, No. 1, 2004, pp. 65-71. doi:10.1111/j.1349-7006.2004.tb03172.x

[5] K. D. Setchell, N. M. Brown and E. Lydeking-Olsen,
"The Clinical Importance of the Metabolite Equol-A Clue to the Effectiveness of Soy and Its Isoflavones," Journal of Nutrition, Vol. 132, No. 12, 2002, pp. 3577-3584.

[6] T. Ueno, S. Uchiyama and N. Kikuchi, "The Role of Intestinal Bacteria on Biological Effects of Soy Isoflavones in Human," Journal of Nutrition, Vol. 132, 2002, p. 594S.

[7] E. Lydeking-Olsen, J. B. E. Jensen, K. D. R. Setchell, M. Damhus and T. H. Jensen, "Isoflavone-Rich Soymilk Prevents Bone-Loss in the Lumbar Spine of Postmenopausal Women. A 2 Year Study," Journal of Nutrition, Vol. 132, 2002, p. 581S.

[8] T. Maruo, M. Sakamoto, C. Ito, T. Toda and Y. Benno, "Adlercreutzia Equolifaciens gen. nov., sp. nov., an Equol-Producing Bacterium Isolated from Human Faeces, and Emended Description of the Genus Eggerthella," International Journal of Systematic and Evolutionary Microbiology, Vol. 58, Pt. 5, 2008, pp. 1221-1227.

[9] S. Uchiyama, T. Ueno and T. Suzuki, "Identification of a Newly Isolated Equol-Producing Lactic Acid Bacterium from the Human Feces," Journal of Intestinal Microbiology, Vol. 21, No. 3, 2007, pp. 217-220 [in Japanese].

[10] K. Hirayama, "Metabolism of Soy Isoflavones by Intestinal Flora," Journal of Intestestinal Microbiology, Vol. 19, No. 1, 2005, pp. 17-23 [in Japanese].

[11] T. J. Lundh, H. Pettersson and K. H. Kiessling, "Liquid Chromatographic Determination of the Estrogens Daidzein, Formononetin, Coumestrol, and Equol in Bovine Blood Plasma and Urine," Journal of the Association of Official Analytical Chemists, Vol. 71, No. 5, 1988, pp. 938-941.

[12] A. A. Franke and L. J. Custer, "High-Performance Liquid Chromatographic Assay of Isoflavonoids and Coumestrol from Human Urine," Journal of Chromatography B: Biomedical Sciences and Applications, Vol. 662, No. 1, 1994, pp. 47-60. doi:10.1016/0378-4347(94)00390-4

[13] L. Coward, M. Kirk, N. Albin and S. Barnes, "Analysis of Plasma Isoflavones by Reversed-Phase HPLC-Multiple Reaction Ion Monitoring-Mass Spectrometry," Clinica Chimica Acta, Vol. 247, No. 1-2, 1996, pp. 121-142. doi:10.1016/0009-8981(95)06242-4

[14] E. Brouwers, R. L'homme, N. Al-Maharik, O. Lapcík, R. Hampl, K. Wähälä, H. Mikola and H. Adlercreutz, "Time-Resolved Fluoroimmunoassay for Equol in Plasma and Urine," Journal of Steroid Biochemistry and Molecular Biology, Vol. 84, No. 5, 2003, pp. 577-588. doi:10.1016/S0960-0760(03)00071-2

[15] D. C. Talbot, R. M. Ogborne, T. Dadd, H. Adlercreutz, G. Barnard, S. Bugel, F. Kohen, S. Marlin, J. Piron, A. Cassidy and J. Powell, "Monoclonal Antibody-Based Time-Resolved Fluorescence Immunoassays for Daidzein, Genistein, and Equol in Blood and Urine: Application to the Isoheart Intervention Study," Clinical Chemistry, Vol. 53, No. 4, 2007, pp. 748-756. doi:10.1373/clinchem.2006.075077

[16] T. Minekawa, A. Kambegawa, K. Shindome, H. Ohkuma, K. Abe, H. Maekawa and H. Arakawa, "Development of Bioluminescent Enzyme Immunoassay for S-Equol Using Firefly Luciferase and Its Application to the Assessment of Equol-Producer Status," Chemical and Pharmaceutical 
Bulletin, Vol. 59, No. 1, 2011, pp. 84-87. doi: $10.1248 / \mathrm{cpb} .59 .84$

[17] H. Adlercreutz, J. van der Wildt, J. Kinzel, H. Attalla, K. Wähälä, T. Mäkelä, T. Hase and T. Fotsis, "Lignan and Isoflavonoid Conjugates in Human Urine," Journal of Steroid Biochemistry and Molecular Biology, Vol. 52, No. 1, 1995, pp. 97-103. doi:10.1016/0960-0760(94)00146-D

[18] K. D. Setchell, C. Clerici, E. D. Lephart, S. J. Cole, C. Heenan, D. Castellani, B. E. Wolfe, L. NechemiasZimmer, N. M. Brown, T. D. Lund, R. J. Handa and J. E.
Heubi, "S-Equol, a Potent Ligand for Estrogen Receptor Beta, Is the Exclusive Enantiomeric form of the Soy Isoflavone Metabolite Produced by Human Intestinal Bacterial Flora," The American Journal of Clinical Nutrition, Vol. 81, No. 5, 2005, pp. 1072-1079.

[19] K. D. Setchell, N. M. Brown, P. Desai, L. ZimmerNechemias, B. E. Wolfe, W. T. Brashear, A. S. Kirschner, A. Cassidy and J. E. Heubi, "Bioavailability of Pure Isoflavones in Healthy Humans and Analysis of Commercial Soy Isoflavone Supplements," Journal of Nutrition, Vol. 131, No. 4-Suppl, 2001, pp. 1362S-1375S. 